\title{
A Novel Three-Gene Model Predicts Prognosis and Therapeutic Sensitivity in Esophageal Squamous Cell Carcinoma
}

\author{
Fa-Min Zeng, ${ }^{1,2,3}$ Jian-Zhong He, ${ }^{1,2,4}$ Shao-Hong Wang, ${ }^{5}$ De-kai Liu, ${ }^{1,2,6}$ Xiu-E. Xu, ${ }^{1,2}$ \\ Jian-Yi Wu, ${ }^{1,2}$ En-Min Li $\left(\mathbb{D},{ }^{1,2}\right.$ and Li-Yan Xu $\mathbb{1}{ }^{1,2}$ \\ ${ }^{1}$ The Key Laboratory of Molecular Biology for High Cancer Incidence Coastal Chaoshan Area, \\ Shantou University Medical College, Shantou, Guangdong, China \\ ${ }^{2}$ Department of Biochemistry and Molecular Biology, Shantou University Medical College, Shantou, Guangdong, China \\ ${ }^{3}$ Guangdong Provincial Engineering Research Center of Molecular Imaging, The Fifth Affiliated Hospital, Sun Yat-sen University, \\ Zhuhai, Guangdong, China \\ ${ }^{4}$ Department of Pathology, The Fifth Affiliated Hospital, Sun Yat-sen University, Zhuhai, Guangdong, China \\ ${ }^{5}$ Department of Pathology, Shantou Central Hospital, Affiliated Shantou Hospital of Sun Yat-sen University, Shantou, \\ Guangdong, China \\ ${ }^{6}$ Department of Medical Records Management, Shenzhen People's Hospital, Shenzhen, Guangdong, China
}

Correspondence should be addressed to En-Min Li; nmli@stu.edu.cn and Li-Yan Xu; lyxu@stu.edu.cn

Received 25 September 2019; Accepted 7 November 2019; Published 25 November 2019

Guest Editor: Amal El-Naggar

Copyright (c) 2019 Fa-Min Zeng et al. This is an open access article distributed under the Creative Commons Attribution License, which permits unrestricted use, distribution, and reproduction in any medium, provided the original work is properly cited.

\begin{abstract}
To precisely predict the clinical outcome and determine the optimal treatment options for patients with esophageal squamous cell carcinoma (ESCC) remains challenging. Prognostic models based on multiple molecular markers of tumors have been shown to have superiority over the use of single biomarkers. Our previous studies have identified the crucial role of ezrin in ESCC progression, which prompted us to hypothesize that ezrin-associated proteins contribute to the pathobiology of ESCC. Herein, we explored the clinical value of a molecular model constructed based on ezrin-associated proteins in ESCC patients. We revealed that the ezrin-associated proteins (MYC, PDIA3, and ITGA5B1) correlated with the overall survival (OS) and disease-free survival (DFS) of patients with ESCC. High expression of MYC was associated with advanced pTNM-stage $(P=0.011)$, and PDIA3 and ITGA5B1 were correlated with both lymph node metastasis (PDIA3: $P<0.001$; ITGA5B1: $P=0.001$ ) and pTNM-stage (PDIA3: $P=0.001$; ITGA5B1: $P=0.009$ ). Furthermore, we found that, compared with the current TNM staging system, the molecular model elicited from the expression of MYC, PDIA3, and ITGA5B1 shows higher accuracy in predicting OS $(P<0.001)$ or DFS $(P<0.001)$ in ESCC patients. Moreover, ROC and regression analysis demonstrated that this model was an independent predictor for OS and DFS, which could also help determine a subgroup of ESCC patients that may benefit from chemoradiotherapy. In conclusion, our study has identified a novel molecular prognosis model, which may serve as a complement for current clinical risk stratification approaches and provide potential therapeutic targets for ESCC treatment.
\end{abstract}

\section{Introduction}

Esophageal cancer is the sixth leading cause of cancer-related deaths and the eighth most common type of malignant gastrointestinal cancer in the world $[1,2]$. Adenocarcinoma and squamous cell carcinoma (ESCC) are the two major types of esophageal cancer, with the latter accounting for the $90 \%$ of cases worldwide [3]. In China, ESCC still remains the highest incidence and cancer-induced mortality rates, and the long-term prognosis of patients with ESCC is less than $20 \%$, despite improvements in treatments such as surgical resection and adjuvant chemoradiation $[4,5]$. This poor prognosis for ESCC patients is highly associated with the difficult nature of diagnosing early-stage ESCC and the frequent occurrence of local invasion and distant metastasis [5]. In addition, conventional chemotherapy and radiotherapy treatments are relatively ineffective [6]. Therefore, seeking novel molecular prognostic markers that can help 
identify patients at high risk and improving their prognosis are urgent needs in the clinic.

However, signal molecular marker cannot meet the clinical requirements for biomarkers, such as high sensitivity and specificity, and it is more accurate than the current clinical staging system [7]. In the last few years, studies have demonstrated that combinations of multiple biomarkers were more sensitive and reliable than single molecular marker. Although several prognostic biomarkers for ESCC have been reported [8-12], there is still no ideal biomarker for clinical use.

Ezrin as a member of the ezrin/radixin/moesin (ERM) protein family plays an important role in regulating the growth and metastatic of cancer $[13,14]$. In our previous studies, we showed that ezrin was upregulated in ESCC and promoted cellular proliferation and invasiveness of ESCC cells [15]. Furthermore, Ezrin might be a new prognostic molecular marker for ESCC patients [16]. Ezrin was also known as a key molecule connected with many other molecules in the biology of tumor development [17]. In these ezrin-related proteins, our previous studies identified that three proteins, i.e., MYC, PDIA3, and ITGA5B1, correlated with patients' survival $[11,12]$. MYC, a protooncogene, plays an integral role in a variety of normal cellular functions [18]. MYC amplification is a recurrent event in many tumors and contributes to tumor development and progression [19-22]. The progress of MYCinduced tumorigenesis in prostate cancer cells entails MYC binding to the ezrin gene promoter and the induction of its transcription [23]. Meanwhile, the induction of ezrin expression is essential for MYC-stimulated invasion [23]. PDIA3 (protein disulfide isomerase family A, member 3), also known as ERp57, is one of the main members of the protein disulfide isomerase (PDI) gene family and is identified primarily as enzymatic chaperones for reconstructing misfolded proteins within the endoplasmic reticulum (ER) [24]. Several studies have linked PDIA3 to different types of cancer, including breast [25], ovarian [26], and colon [27] cancers. In ESCC, we found that PDIA3 interacted with ezrin, and it was not only involved in the development and progression of ESCC but also related to OS and DFS of ESCC patients [12]. ITGA5B1 is a member of the integrin family which plays a significant role in cell adhesion to the extracellular matrix (ECM) [28, 29]. In ESCC, ITGA5B1 upregulates the expression of ezrin through the L1CAM [30].

Although ezrin plays a pivotal role in ESCC progression, the clinical significance of ezrin-related proteins (MYC, PDIA3, and ITGA5B1) has not been thoroughly investigated in ESCC patients. Clinicopathological analyses of these ezrin-interacting proteins may further our understanding of the function of ezrin and provide therapeutic targets for ESCC. In the current study, we found that a three-gene signature comprised of MYC, PDIA3, and ITGA5B1 could independently predict ESCC patient survival.

\section{Materials and Methods}

2.1. Patients and Specimens. For this retrospective study, 284 cases of formalin-fixed, paraffin-embedded ESCC tissue were collected from the Shantou Central Hospital between November 2007 and January 2010. All patients underwent curative resection and were confirmed as having ESCC by pathologists in the Clinical Pathology Department of the Hospital. Information on age, gender, and histopathological factors was obtained from the medical records and shown in Table 1. An independent validation set (GSE53622 and GSE5364) was obtained from the publicly available GEO database (https://www.ncbi.nlm.nih.gov/). We excluded the ESCC patients without clinical survival information, and the clinicopathological information was shown in Table S1. Overall survival (OS) was defined as the interval between surgery and death from tumors or between surgery and the last observation taken for surviving patients. Disease-free survival (DFS) was defined as the interval between surgery and diagnosis of relapse or death. Ethical approval was obtained from the ethical committee of the Central Hospital of Shantou City and the ethical committee of the Medical College of Shantou University, and only resected samples from surgical patients giving written informed consent were included for use in research.

\subsection{Tissue Microarrays (TMAs) and Immunohistochemistry} (IHC). TMAs were constructed based on standard techniques as previously described [12]. IHC was performed using the PV-9000 2-step Polymer Detection System (ZSGB$\mathrm{BIO}$, Beijing, China) and Liquid DAB Substrate Kit (Invitrogen, San Francisco, CA) according to the manufacturer's instructions and has been described in our previous studies [12]. The primary mouse monoclonal MYC antibody (1:100 dilution; Santa Cruz Biotechnology, USA), anti-PDIA3 antibody (polyclonal, 1:700 dilution; sigma, Saint Louis, $\mathrm{MO}$ ), and anti-ITGA5B1 antibody (monoclonal, 1:50 dilution; millipore, USA) were used in this study.

2.3. Evaluation of IHC Variables. The protein expression was evaluated by an automated quantitative pathology imaging system (PerkinElmer, Waltham, MA, USA), as described previously [11]. Briefly, as shown in Figure S1, the automated image acquisition and color images were obtained using Vectra 2.0.8 software. Subsequently, the spectral libraries were constructed using Nuance 3.0 software. And then, the color images were evaluated by Inform 1.2 software as follows: (1) segmentation of the tumor region from the tissue compartments, (2) segmentation of the tumor region from the tumor region, and (3) $\mathrm{H}$ score calculation $(=(\%$ at $0) * 0+(\%$ at $1+) * 1+(\%$ at $2+) * 2+(\%$ at $3+) * 3)$ based on the optical density which produces a continuous protein expression value in the range of 0 to 300 .

2.4. Construction of a Survival Predictive Model. Firstly, we used a univariate Cox proportional hazards regression analysis to evaluate the correlation between survival and each protein. Subsequently, we constructed a predictive model by the summation of the expression of each biomarker (high $=1$, low $=0$ ) multiplied by its regression coefficient, as described in the following equation: $Y=(\beta 1) \times \mathrm{MYC}+(\beta 2) \times \mathrm{PDIA} 3+(\beta 3) \times$ ITGA5B1 [9]. Patients were then divided into three groups (high-risk, medium-risk, and low-risk) by the cut-off value generated by X-tile software [31]. 
TABLE 1: The clinicopathological characteristics of generation dataset of patients with ESCC.

\begin{tabular}{|c|c|c|c|c|c|}
\hline Clinical and pathological indexes & Case no. & 5 -year OS (\%) & $P^{*}$ & 5-year DFS (\%) & $P^{*}$ \\
\hline Specimens & 284 & & & & \\
\hline Mean age & 58.7 & & & & \\
\hline \multicolumn{6}{|l|}{ Age (year) } \\
\hline$\leq 58$ & 148 & 48.1 & \multirow{2}{*}{0.036} & 43.4 & \multirow{2}{*}{0.207} \\
\hline$>58$ & 136 & 39.1 & & 35.8 & \\
\hline \multicolumn{6}{|l|}{ Gender } \\
\hline Male & 220 & 44.8 & \multirow{2}{*}{0.387} & 40.5 & \multirow{2}{*}{0.915} \\
\hline Female & 64 & 40.2 & & 37.2 & \\
\hline \multicolumn{6}{|l|}{ Therapies } \\
\hline Only surgery & 160 & 45.2 & \multirow{4}{*}{0.080} & 42.0 & \multirow{4}{*}{0.070} \\
\hline Surgery + radiotherapy & 39 & 53.6 & & 51.3 & \\
\hline Surgery + chemotherapy & 57 & 46.2 & & 36.4 & \\
\hline Surgery + chemoradiotherapy & 28 & 17.9 & & 17.9 & \\
\hline \multicolumn{6}{|l|}{ Tumor size } \\
\hline$\leq 3 \mathrm{~cm}$ & 67 & 55.6 & \multirow{3}{*}{0.057} & 54.4 & \multirow{3}{*}{0.021} \\
\hline $3-5 \mathrm{~cm}$ & 134 & 43.5 & & 37.9 & \\
\hline$>5 \mathrm{~cm}$ & 83 & 34.7 & & 31.1 & \\
\hline \multicolumn{6}{|l|}{ Tumor location } \\
\hline Upper & 16 & 33.5 & \multirow{3}{*}{0.463} & 25.0 & \multirow{3}{*}{0.127} \\
\hline Middle & 122 & 45.6 & & 44.8 & \\
\hline Lower & 146 & 43.3 & & 37.2 & \\
\hline \multicolumn{6}{|l|}{ Histologic grade } \\
\hline G1 & 45 & 57.7 & \multirow{3}{*}{0.001} & 57.7 & \multirow{3}{*}{$<0.001$} \\
\hline G2 & 219 & 43.5 & & 38.3 & \\
\hline G3 & 20 & 15.0 & & 15.0 & \\
\hline \multicolumn{6}{|l|}{ Invasive depth } \\
\hline $\mathrm{T} 1$ & 13 & 84.6 & \multirow{3}{*}{0.005} & 84.6 & \multirow{3}{*}{0.013} \\
\hline $\mathrm{T} 2$ & 42 & 50.0 & & 45.2 & \\
\hline T3 & 229 & 40.2 & & 36.2 & \\
\hline \multicolumn{6}{|l|}{ Lymph node metastasis } \\
\hline No & 141 & 58.1 & \multirow{4}{*}{$<0.001$} & 53.5 & \multirow{4}{*}{$<0.001$} \\
\hline N1 & 81 & 44.0 & & 39.0 & \\
\hline $\mathrm{N} 2$ & 46 & 15.2 & & 13.0 & \\
\hline N3 & 16 & 0.0 & & 0.0 & \\
\hline \multicolumn{6}{|l|}{ pTNM-stage } \\
\hline I & 23 & 82.6 & \multirow{3}{*}{$<0.001$} & 82.6 & \multirow{3}{*}{$<0.001$} \\
\hline II & 131 & 54.2 & & 49.2 & \\
\hline III & 130 & 26.4 & & 22.6 & \\
\hline
\end{tabular}

${ }^{*}$ Log-rank test of Kaplan-Meier method; $P<0.05$ was considered significant. All patients underwent surgical treatment. OS: overall survival. DFS: disease-free survival.

2.5. Statistical Analysis. The SPSS v19.0 program was used for statistical analysis. Cumulative survival time was calculated by the Kaplan-Meier (K-M) method and analyzed by the log-rank test. The association of biomarkers and clinicopathological factors was evaluated by Fisher's exact test. The Cox proportional hazards regression model was used for univariate and multivariate analyses. The predictive value of the parameters was determined by receiver operating characteristic (ROC) curve analysis. $P<0.05$ was considered to be statistically significant.

\section{Results}

3.1. Immunohistochemical Characteristics of 3 Biomarkers. The expression levels of MYC, PDIA3, and ITGA5B1 protein in ESCC were examined by IHC. As shown in Figure 1(a), MYC, PDIA3, and ITGA5B1 were mainly localized in the cytoplasm. We further investigated the association between the expression of these 3 biomarkers and clinicopathological parameters. There was no significant correlation between the 3 markers and age, gender, tumor size, histologic grade, or invasive depth, etc. Nonetheless, low-expression of PDIA3 or high expression of ITGA5B1 significantly correlated with lymph node (LN) metastasis, whereas no correlation was found between MYC and LN metastasis (Table 2). In addition, PDIA3 had a negative correlation while MYC and ITGA5B1 had a positive correlation with pTNM-stage (Table 2). In support of these correlation analyses, MYC and ITGA5B1 showed increased expression in tumors with high clinical stage; in contrast, PDIA3 expression was downregulated in stage III tumors compared with those with stages I and II (Figure 1(b)).

3.2. Prognostic Significance of MYC, PDIA3, and ITGA5B1 in Patients with ESCC. To further explore the clinical 

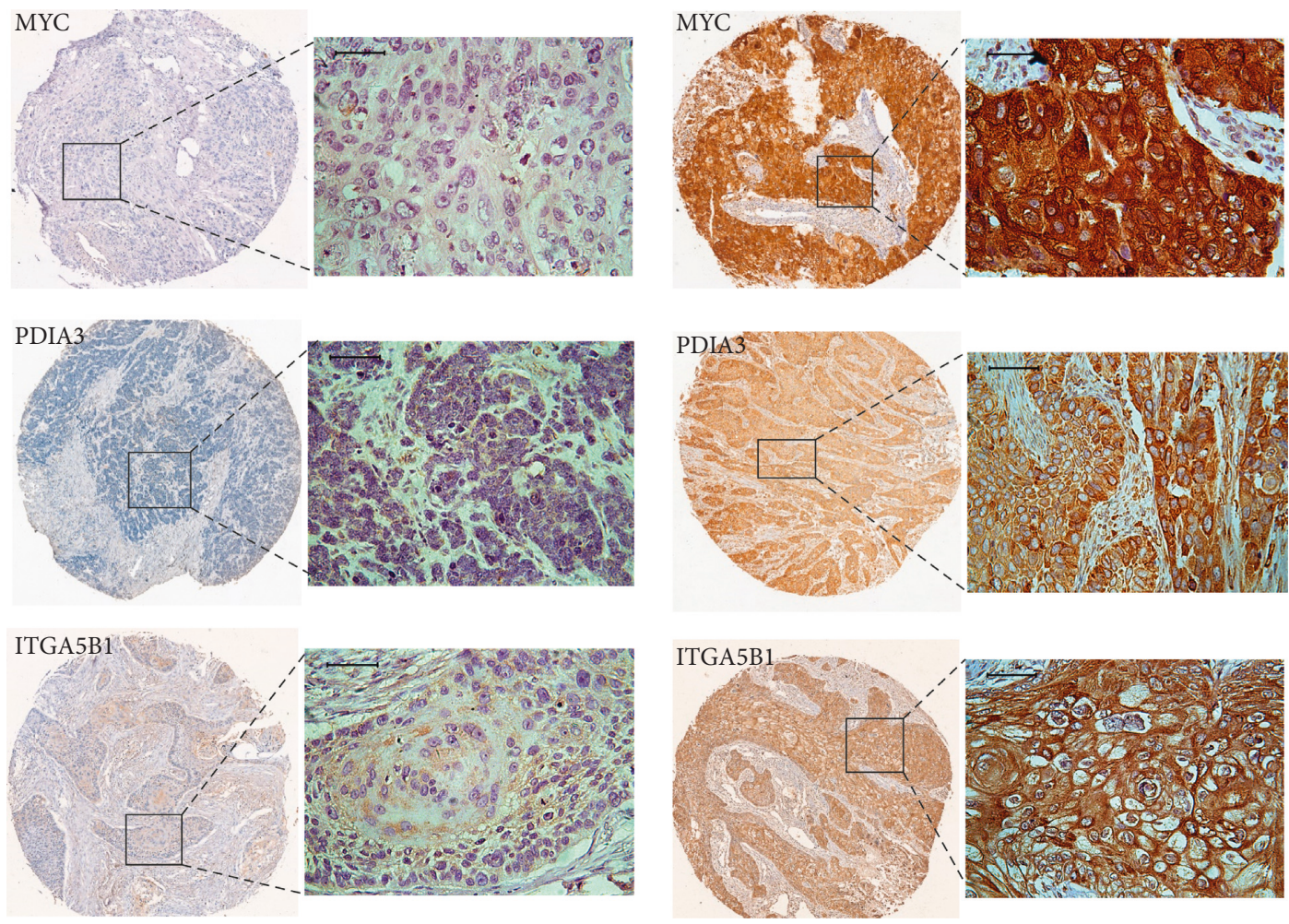

(a)
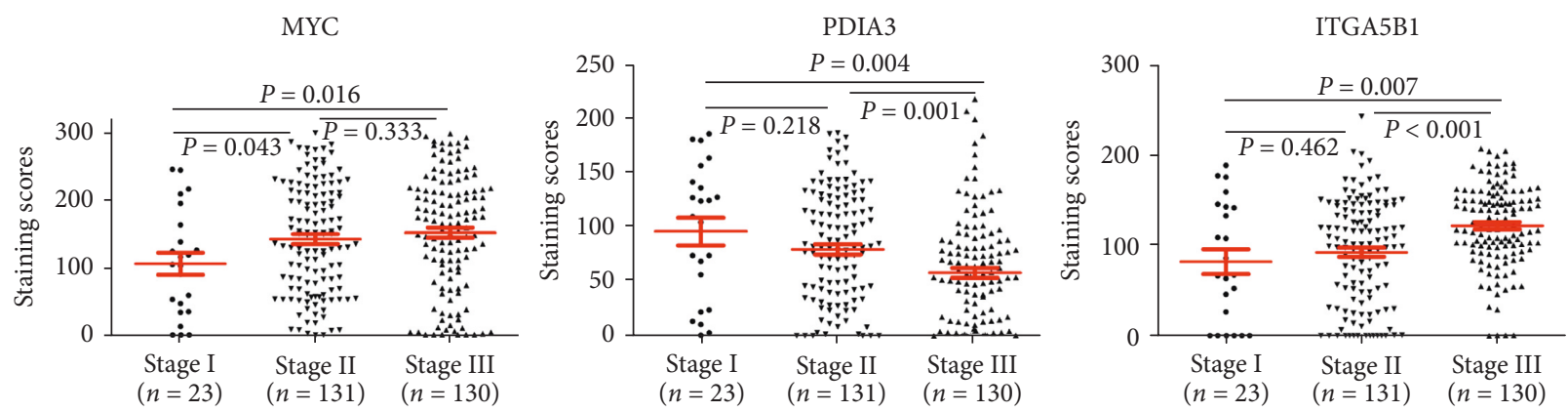

(b)

FIGURE 1: Expression of MYC, PDIA3, and ITGA5B1 in ESCC. (a) Representative images of IHC staining for MYC, PDIA3, and ITGA5B1 in ESCC samples (scale bars $=50 \mu \mathrm{m}$ ). (b) The H scores of MYC, PDIA3, and ITGA5B in different clinical stages (stages I, II, and III) of ESCC were shown by scatter diagram $(P<0.05$, independent-samples $t$-test).

significance of MYC, PDIA3, and ITGA5B1 in ESCC patients, Kaplan-Meier analysis and log-rank test were performed. As shown in Figure 2, high expression of MYC or ITGA5B1 was significantly associated with poor prognosis (MYC: OS, $P=0.024$, DFS, $P=0.024$; ITGA5B1: OS, $P=0.001$, DFS, $P=0.009$, Figures $2(\mathrm{a})$ and $2(\mathrm{c}))$. However, the overexpression of PDIA3 trended to predict a favorable OS $(P=0.002)$ and DFS $(P=0.003$, Figure $2(b))$. Besides, because ITGA5B1 is a heterodimer of alpha and beta subunit, we used the expression level of ITGA5 instead of ITGA5B1 in microarray data, and the predictive value of MYC, PDIA3, and ITGA5 was further validated in an independent cohort (GSE53622 and GSE5364).

The results for validation set were in line with those in generation set (Supplementary Figure S2(a)). Univariate
Cox regression analysis further identified that these 3 molecules were significantly associated with OS (MYC: $P=0.026$; PDIA3: $P=0.003$; ITGA5B1: $P=0.001)$ and DFS (MYC: $P=0.026$; PDIA3: $P=0.004$; ITGA5B1: $P=0.010$, Table 3).

3.3. A Molecular Prognostic Model of the 3 Biomarkers Signature. We then evaluated the prognostic value of a molecular model that takes consideration of all the 3 biomarkers. To this end, we calculated the risk score $Y=(\beta 1) *(\mathrm{MYC})+(\beta 2) *($ PDIA3 $)+(\beta 3) *($ ITGA5B1 $)$. In this dataset, the regression coefficients $(\beta 1=0.347$, $\beta 2=-0.482, \beta 3=0.501$ ) were calculated by univariate Cox proportional hazards analysis. All patients were divided into 
TABLE 2: The correlation between 3 markers and clinicopathological characteristics in ESCC.

\begin{tabular}{|c|c|c|c|c|c|c|c|c|c|}
\hline \multirow{2}{*}{ Variables } & \multicolumn{2}{|c|}{$\mathrm{MYC}^{\mathrm{a}}$} & \multirow{2}{*}{$P^{*}$} & \multicolumn{2}{|c|}{ PDIA $^{\mathrm{b}}$} & \multirow{2}{*}{$P^{*}$} & \multicolumn{2}{|c|}{ ITCA5B1 $^{\mathrm{c}}$} & \multirow{2}{*}{$P^{*}$} \\
\hline & Low & High & & Low & High & & Low & High & \\
\hline \multicolumn{10}{|l|}{ Age (year) } \\
\hline$\leq 58$ & 67 & 81 & \multirow{2}{*}{0.425} & 84 & 64 & \multirow{2}{*}{0.725} & 92 & 56 & \multirow{2}{*}{0.334} \\
\hline$>58$ & 68 & 68 & & 80 & 56 & & 92 & 44 & \\
\hline \multicolumn{10}{|l|}{ Gender } \\
\hline Male & 109 & 111 & \multirow{2}{*}{0.208} & 127 & 93 & \multirow{2}{*}{0.990} & 137 & 83 & \multirow{2}{*}{0.100} \\
\hline Female & 26 & 38 & & 37 & 27 & & 47 & 17 & \\
\hline \multicolumn{10}{|l|}{ Therapies } \\
\hline Only surgery & 85 & 75 & \multirow{4}{*}{0.067} & 97 & 63 & \multirow{4}{*}{0.588} & 107 & 53 & \multirow{4}{*}{0.849} \\
\hline Surgery + radiotherapy & 14 & 25 & & 20 & 19 & & 25 & 14 & \\
\hline Surgery + chemotherapy & 21 & 36 & & 30 & 27 & & 35 & 22 & \\
\hline Surgery + radiochemotherapy & 15 & 13 & & 17 & 11 & & 17 & 11 & \\
\hline \multicolumn{10}{|l|}{ Tumor size } \\
\hline$\leq 3 \mathrm{~cm}$ & 39 & 28 & \multirow{3}{*}{0.101} & 41 & 26 & \multirow{3}{*}{0.303} & 43 & 24 & \multirow{3}{*}{0.489} \\
\hline $3-5 \mathrm{~cm}$ & 62 & 72 & & 71 & 63 & & 83 & 51 & \\
\hline$>5 \mathrm{~cm}$ & 34 & 49 & & 52 & 31 & & 58 & 25 & \\
\hline \multicolumn{10}{|l|}{ Tumor location } \\
\hline Upper & 6 & 10 & \multirow{3}{*}{0.307} & 9 & 7 & \multirow{3}{*}{0.383} & 8 & 8 & \multirow{3}{*}{0.395} \\
\hline Middle & 64 & 58 & & 65 & 57 & & 82 & 40 & \\
\hline Lower & 65 & 81 & & 90 & 56 & & 94 & 52 & \\
\hline Histologic grade & & & & & & & & & \\
\hline G1 & 25 & 20 & & 20 & 25 & & 32 & 13 & \\
\hline $\mathrm{G} 2$ & 101 & 118 & 0.499 & 129 & 90 & 0.054 & 140 & 79 & 0.588 \\
\hline G3 & 9 & 11 & & 15 & 5 & & 12 & 8 & \\
\hline Invasive depth & & & & & & & & & \\
\hline $\mathrm{T} 1+\mathrm{T} 2$ & 32 & 23 & & 37 & & & & 21 & \\
\hline $\mathrm{T} 3+\mathrm{T} 4$ & 103 & 126 & 0.078 & 127 & 102 & 0.111 & 150 & 79 & 0.607 \\
\hline Lymph node metastasis & & & & & & & & & \\
\hline No & 73 & 68 & & 64 & 77 & & 105 & 36 & 0.001 \\
\hline $\mathrm{N} 1+\mathrm{N} 2+\mathrm{N} 3$ & 62 & 81 & 0.156 & 100 & 43 & $<0.001$ & 79 & 64 & 0.001 \\
\hline pTNM-stage & & & & & & & & & \\
\hline I & 17 & 6 & & 10 & 13 & & 16 & 7 & \\
\hline II & 65 & 66 & 0.011 & 64 & 67 & 0.001 & 96 & 35 & 0.009 \\
\hline III & 53 & 77 & & 90 & 40 & & 72 & 58 & \\
\hline
\end{tabular}

*Fisher's exact test. $P$ value $<0.05$ was considered significant.

low-, medium-, and high-risk groups based on the $Y$ scores, and the optimal cut-off values were determined by the X-tile software based on patients' prognosis [31]. Kaplan-Meier analysis further demonstrated that patients in the low-risk group indeed had markedly prolonged survival (OS: $P<0.001$ : DFS: $P<0.001$, Figure 3(a)). The 5-year OS for low-, medium-, and high-risk groups was $62.9 \%, 41.3 \%$, and $24.5 \%$, respectively. Similar results were obtained for 5 -year DFS in those groups, which were $56.0 \%, 37.4 \%$, and $24.5 \%$, respectively (Figure 3(a)). To validate whether this molecular prognostic model can serve as an independent predictor for OS and DFS, we carried out both univariate and multivariate analyses. As shown in Table 3, our newly defined molecular prognostic model, along with pTNM-stage and tumor size, was independent prognostic factors (Table 3). Moreover, receiver operating characteristic (ROC) analysis indicated that the predictive power of this molecular prognostic model was higher compared to each biomarker individually or the pTNM-stage (Figure 3(b)). The predictive value and power of molecular model for OS also yielded similar results from validation set as shown in Figure S2(b).

3.4. The Potential of the Molecular Prognostic Model in Identifying ESCC Patients Who Can Benefit from Chemoradiotherapy. As shown in Table 1, chemoradiotherapy did not markedly prolong the OS and DFS of ESCC patients. To test the utility of the molecular prognostic model for predicting therapeutic efficacy, we performed K-M survival analysis. Our results showed that the OS and DFS of patients who were treated with surgery only were higher compared with those who received surger$y+$ radiotherapy or surgery + chemotherapy in the low-risk group (Figure 4(a)). However, the opposite was true for patients in the high-risk group, in which ESCC patients who received only surgery had an unfavorable outcome (Figure 4(c)). Radiotherapy and chemotherapy tended to prolong patients' survival as the risk went up as determined 

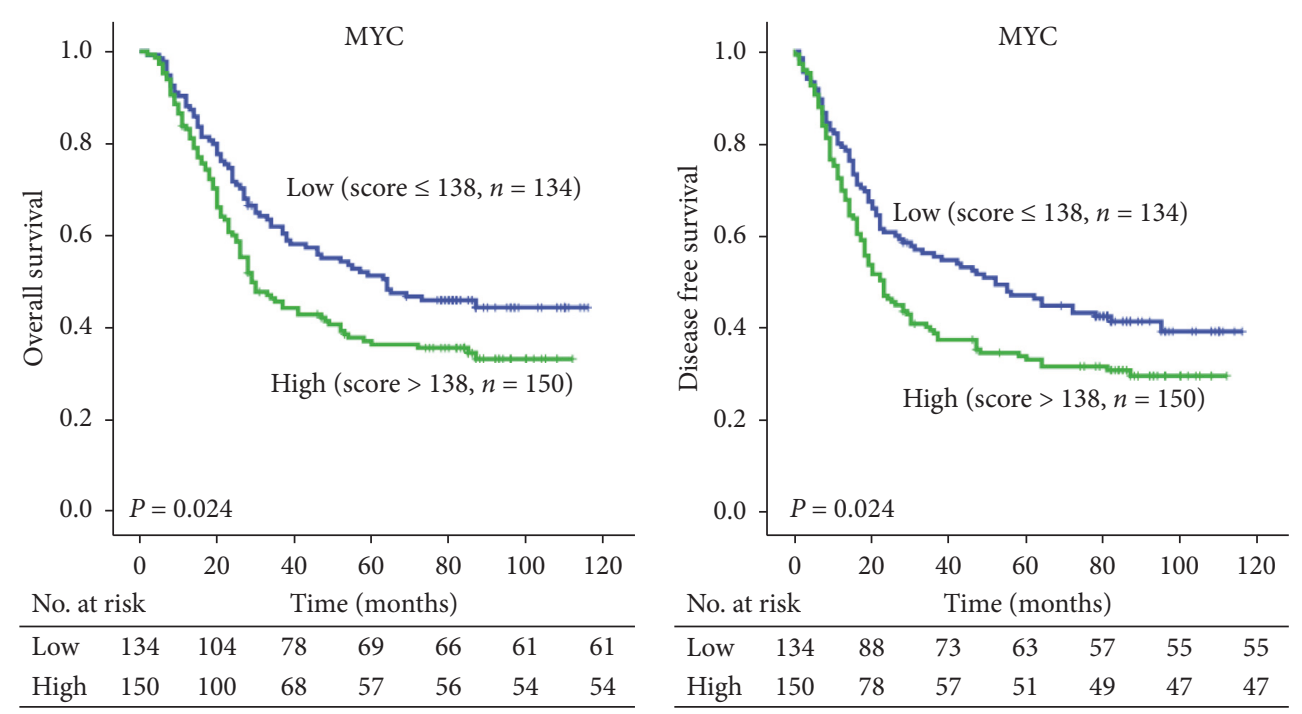

(a)
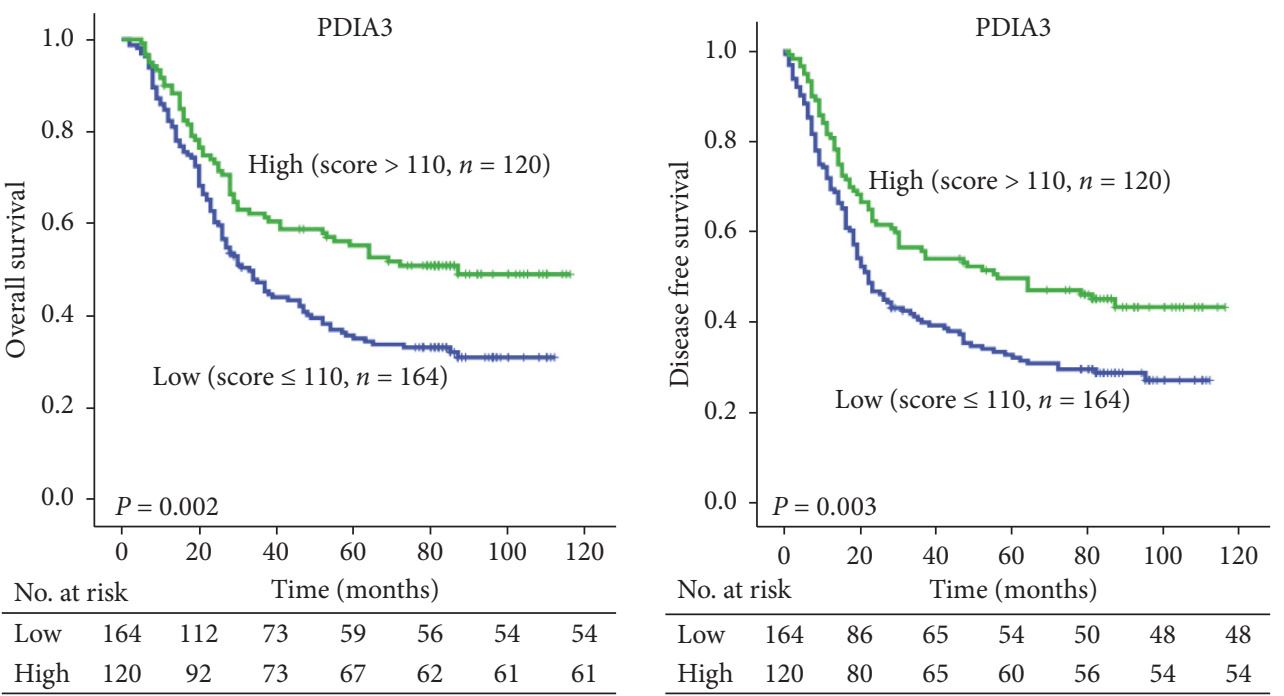

(b)
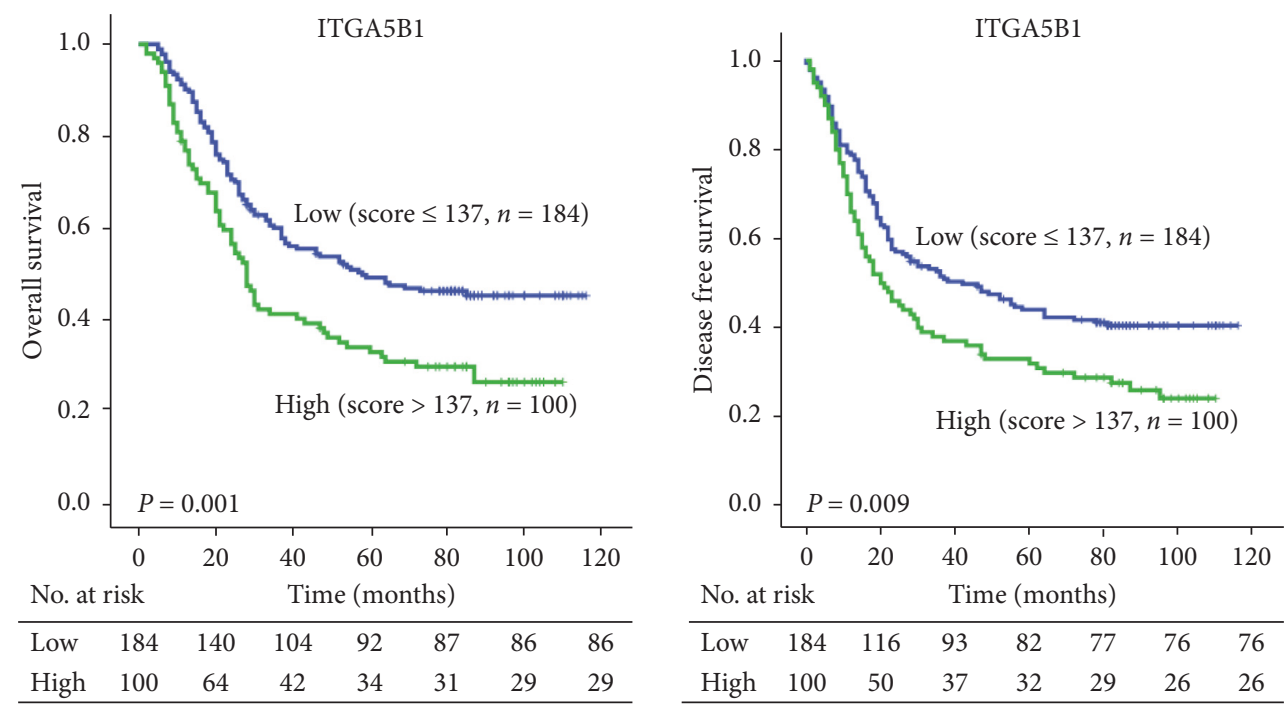

(c)

FIgURE 2: K-M survival analysis in ESCC patients based on the expression of MYC, PDIA3, and ITGA5B1. The H scores of each protein were divided into low and high groups as determined by X-tile, and the number of patients who were at risk at specific times was labeled under the $x$-axis $(P<0.05$, log-rank test). 
TABLE 3: Univariate and multivariate analyses of factors associated with overall survival (OS) and disease-free survival (DFS) in patients with ESCC.

\begin{tabular}{|c|c|c|c|c|c|c|c|c|}
\hline \multirow{3}{*}{ Variables } & \multicolumn{4}{|c|}{ Univariate analysis } & \multicolumn{4}{|c|}{ Multivariate analysis } \\
\hline & \multicolumn{2}{|l|}{ OS } & \multicolumn{2}{|l|}{ DFS } & \multicolumn{2}{|l|}{ OS } & \multicolumn{2}{|l|}{ DFS } \\
\hline & $\mathrm{HR}(95 \% \mathrm{CI})$ & $P$ & $\mathrm{HR}(95 \% \mathrm{CI})$ & $P$ & $\mathrm{HR}(95 \% \mathrm{CI})$ & $P$ & HR $(95 \% \mathrm{CI})$ & $P$ \\
\hline Age (>58 vs. $\leq 58)$ & $\begin{array}{c}1.376(1.017 \text { to } \\
1.861)\end{array}$ & 0.039 & $\begin{array}{c}1.203(0.900 \text { to } \\
1.609)\end{array}$ & 0.213 & $\begin{array}{c}1.498(1.082 \text { to } \\
2.073)\end{array}$ & 0.015 & & \\
\hline Gender (female vs. male) & $\begin{array}{c}0.857(0.603 \text { to } \\
1.219)\end{array}$ & 0.391 & $\begin{array}{c}0.981(0.693 \text { to } \\
1.390)\end{array}$ & 0.916 & & & & \\
\hline Therapies & & 0.090 & & 0.080 & & & & \\
\hline $\begin{array}{l}\text { (Surgery + radiotherapy vs. only } \\
\text { surgery) }\end{array}$ & $\begin{array}{c}0.799(0.492 \text { to } \\
1.296)\end{array}$ & 0.363 & $\begin{array}{c}0.893(0.557 \text { to } \\
1.432)\end{array}$ & 0.639 & & & & \\
\hline $\begin{array}{l}\text { (Surgery + chemotherapy vs. only } \\
\text { surgery) }\end{array}$ & $\begin{array}{c}0.918(0.642 \text { to } \\
1.423)\end{array}$ & 0.825 & $\begin{array}{c}1.225(0.847 \text { to } \\
1.770)\end{array}$ & 0.281 & & & & \\
\hline $\begin{array}{l}\text { (Surgery + radiochemotherapy } \\
\text { vs. only surgery) }\end{array}$ & $\begin{array}{c}0.918 \text { (1.036 to } \\
2.550)\end{array}$ & 0.035 & $\begin{array}{c}1.701(1.087 \text { to } \\
2.662)\end{array}$ & 0.020 & & & & \\
\hline Tumor size & & 0.062 & & 0.025 & & 0.045 & & 0.021 \\
\hline $3-5 \mathrm{~cm}$ vs. $\leq 3 \mathrm{~cm}$ & $\begin{array}{c}1.285(0.860 \text { to } \\
1.921)\end{array}$ & 0.222 & $\begin{array}{l}1.404(0.948 \text { to } \\
2.077)\end{array}$ & 0.090 & $\begin{array}{c}1.378(0.915 \text { to } \\
2.075)\end{array}$ & 0.124 & $\begin{array}{c}1.432(0.964 \text { to } \\
2.130)\end{array}$ & 0.076 \\
\hline$>5 \mathrm{~cm}$ vs. $\leq 3 \mathrm{~cm}$ & $\begin{array}{c}1.657(1.082 \text { to } \\
2.539)\end{array}$ & 0.020 & $\begin{array}{c}1.787 \text { (1.176 to } \\
2.716)\end{array}$ & 0.007 & $\begin{array}{c}1.730(1.124 \text { to } \\
2.664)\end{array}$ & 0.013 & $\begin{array}{l}1.821(1.193 \text { to } \\
2.779)\end{array}$ & 0.005 \\
\hline pTNM-stage (III vs. I + II) & $\begin{array}{c}2.087(1.443 \text { to } \\
3.019)\end{array}$ & $<0.001$ & $\begin{array}{l}1.956(1.376 \text { to } \\
2.780)\end{array}$ & $<0.001$ & $\begin{array}{c}1.876(1.267 \text { to } \\
2.778)\end{array}$ & 0.002 & $\begin{array}{c}1.689(1.162 \text { to } \\
2.456)\end{array}$ & 0.006 \\
\hline MYC & $\begin{array}{c}1.415 \text { (1.043 to } \\
1.920)\end{array}$ & 0.026 & $\begin{array}{c}1.397(1.041 \text { to } \\
1.874)\end{array}$ & 0.026 & & & & \\
\hline PDIA3 & $\begin{array}{c}0.618(0.450 \text { to } \\
0.848)\end{array}$ & 0.003 & $\begin{array}{c}0.638(0.471 \text { to } \\
0.864)\end{array}$ & 0.004 & & & & \\
\hline ITGA5B1 & $\begin{array}{l}1.651(1.216 \text { to } \\
2.241)\end{array}$ & 0.001 & $\begin{array}{c}1.477(1.098 \text { to } \\
1.986)\end{array}$ & 0.010 & & & & \\
\hline Molecular prognostic model & & $<0.001$ & & $<0.001$ & & 0.001 & & 0.006 \\
\hline Medium-risk vs. $\leq$ low-risk & $\begin{array}{c}1.830(1.215 \text { to } \\
2.758)\end{array}$ & 0.004 & $\begin{array}{c}1.625(1.111 \text { to } \\
2.378)\end{array}$ & 0.012 & $\begin{array}{c}1.577(1.036 \text { to } \\
2.402)\end{array}$ & 0.034 & $\begin{array}{l}1.493(1.010 \text { to } \\
2.208)\end{array}$ & 0.045 \\
\hline High-risk vs. $\leq$ low-risk & $\begin{array}{c}2.914 \text { (1.828 to } \\
4.680)\end{array}$ & $<0.001$ & $\begin{array}{c}2.457 \text { (1.580 to } \\
3.823)\end{array}$ & $<0.001$ & $\begin{array}{c}2.539 \text { (1.556 to } \\
4.141)\end{array}$ & $<0.001$ & $\begin{array}{c}2.122(1.338 \text { to } \\
3.367)\end{array}$ & 0.001 \\
\hline
\end{tabular}

Note. Multivariate analysis, Cox proportional hazards regression model. Variables were adopted for their prognostic significance by univariate analysis.

by our molecular prognostic model. In particular, patients treated with surgery + chemotherapy in the high-risk group had the most favorable OS and DFS compared with surgery alone and surgery + radiotherapy (Figure 4).

\section{Discussion}

ESCC is one of the most prevalent and lethal cancers in Asian [4]; however, there is no effective molecular signatures for predicting the effectiveness of adjuvant treatments and prognosis in the clinic. Previous studies demonstrated that the cytoskeleton changes are intimately associated with cancer invasion and metastasis [32]. In support of this notion, our research has confirmed that the membranecytoskeletal linking protein ezrin contributes significantly to ESCC progression [15]. In this study, we attempted to generate an effective molecular model based on ezrin-related proteins (MYC, PDIA3, and ITGA5B1) for potential clinical applications. Our data highlight that a molecular model elicited from MYC, PDIA3, and ITGA5B1 has superior prognostic values compared with pTNM-stage, which also facilitates the identification of ESCC patients who may benefit from chemoradiotherapy.
Ezrin, a membrane-cytoskeleton linker, plays a major role in promoting tumor progression $[23,33]$. Our previous study has identified the mislocalization of ezrin during ESCC development, in which membranous ezrin in normal epithelial cells becomes cytoplasmic in ESCC [34]. This abnormal localization changes the interacting proteins of ezrin, which has been shown to be critical for regulating tumor cell survival, invasion, and metastasis [12, 17]. The expressions of MYC, PDIA3, and ITGA5B1 have been demonstrated to play critical roles in various malignant tumors and are independent prognostic factors in certain cancers $[12,35,36]$.

It is important to note that although ESCC patients with higher risk predicted by our three-protein molecular model had poor prognosis, these patients might benefit from adjuvant therapies such as chemoradiotherapy, which improved their survival compared with surgical treatment alone. Compared with the model using three different genes (PPARG, MDM2, and NANOG), which we reported in 2015 [9], the current molecular model not only accurately predicts the OS of patients with ESCC but also predicts the DFS and sensitivity to chemoradiation. This makes it much more practical for clinical application. Our results are in line with 

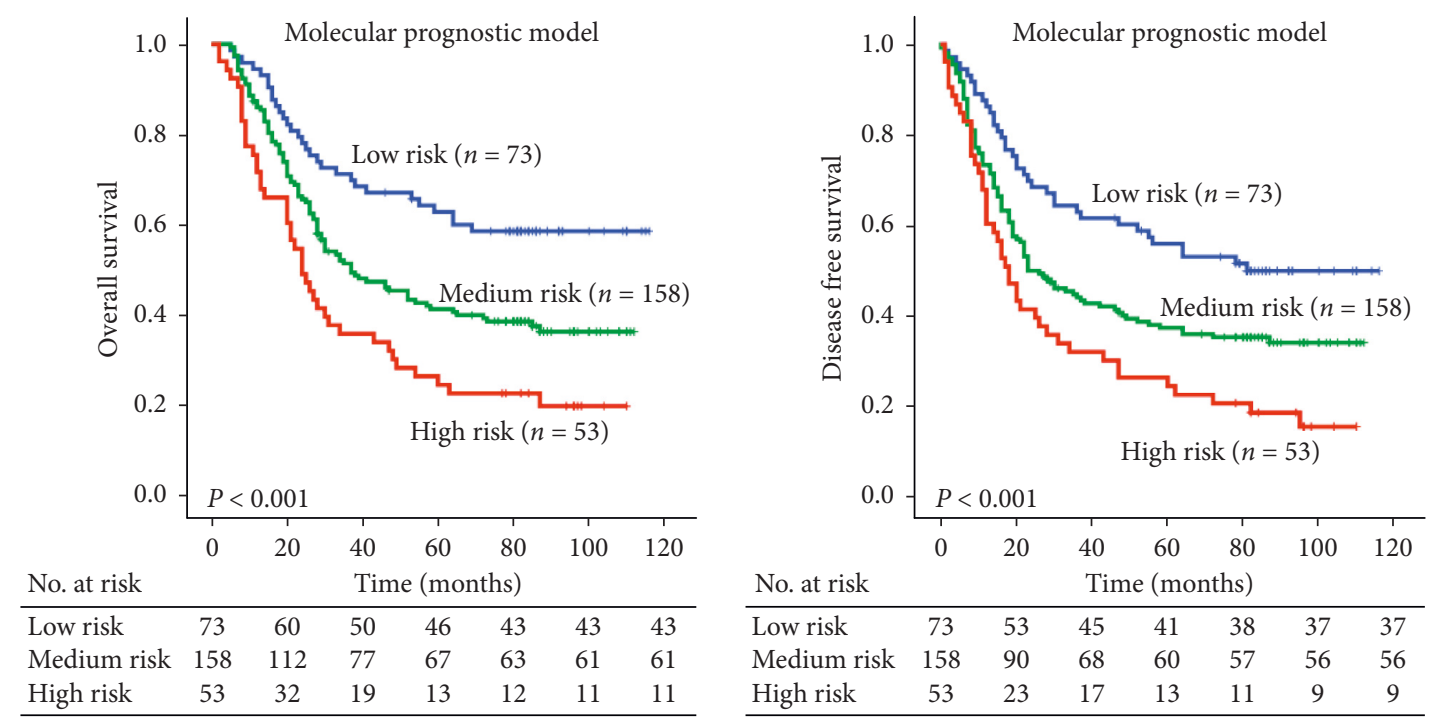

(a)
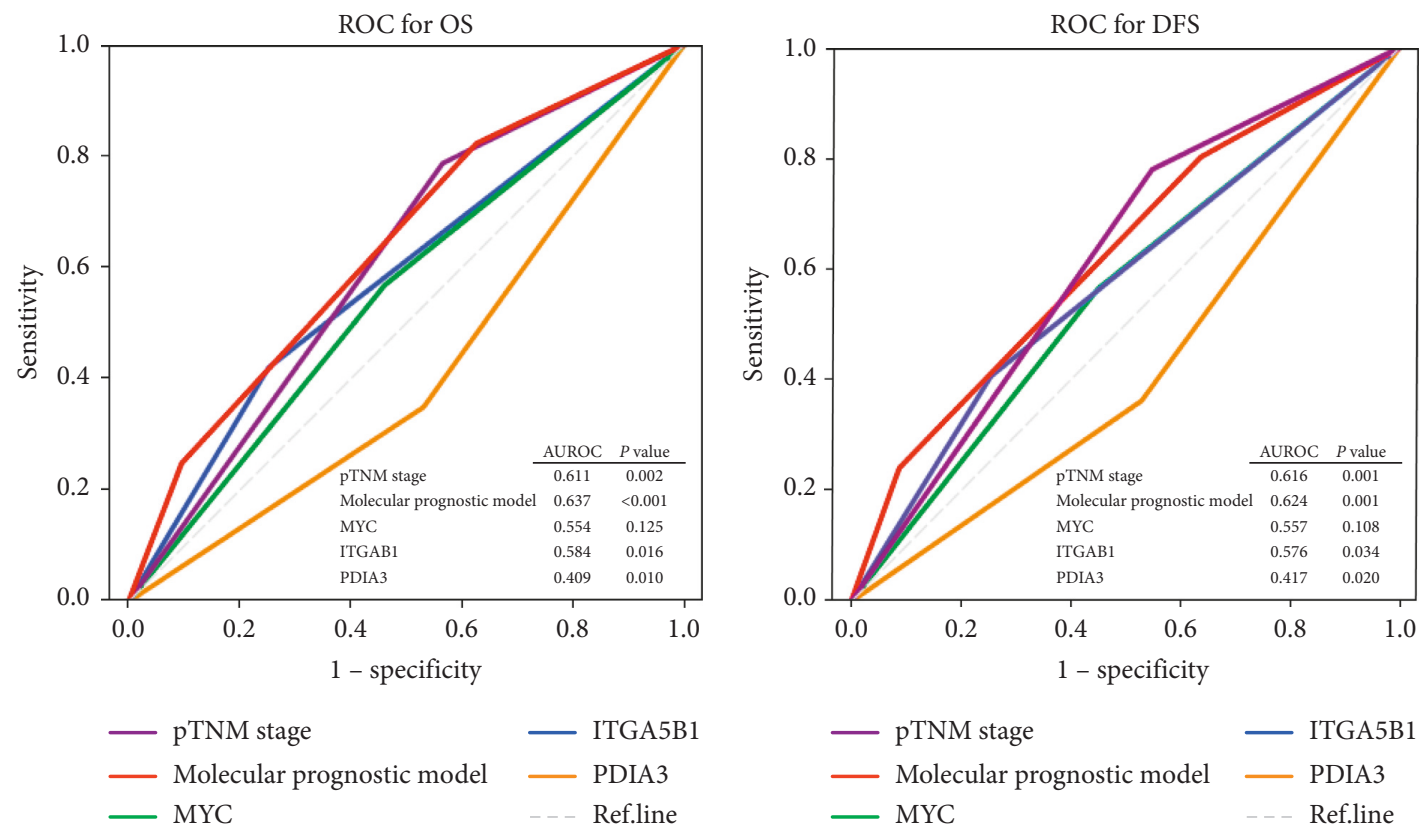

(b)

FIGURE 3: Predictive value of the molecular model. (a) K-M survival curves showing that the OS and DFS had a striking contrast between the ESCC patients in low-, medium-, and high-risk groups. (b) Receiver operating characteristic (ROC) curve was used to evaluate the ability of the molecular model for OS or DFS compared with each biomarker alone or the pTMN-stage.

other clinical studies, which have shown that high expression and rearrangement of MYC are associated with better response to chemoradiotherapy compared with patients without these abnormalities [37, 38]. The mechanism behind this observation is probably related to the biological function of MYC in promoting DNA replication and cell cycle distribution [39]. As chemoradiotherapy utilizes the effects of DNA damage-induced cytotoxicity in neoplastic cells, it is not surprising to see an association between MYC and chemo/ radiosensitivity in ESCC patients. Indeed, overexpression of MYC has been shown to render tumor cells susceptible to chemotherapeutics, such as etoposide, doxorubicin, and camptothecin [40]. Nevertheless, MYC remains an attractive molecular target for therapy due to its high oncogenic properties [41]. Antisense oligonucleotides (ASOs) targeting MYC have been shown to block cell proliferation and induce apoptosis in solid and hematologic tumors [41, 42].

Compared with MYC, relatively little is known about the biological function of ITGA5B1 in carcinoma. Recent studies suggest that ITGA5B1 can prevent cell anoikis through suppressing inflammation- and oxidative stressrelated genes $[43,44]$. ITGA5B1 is especially more noticeable in regulating cell adhesion [45], and it can promote early peritoneal metastasis in serous ovarian cancer [46]. In 

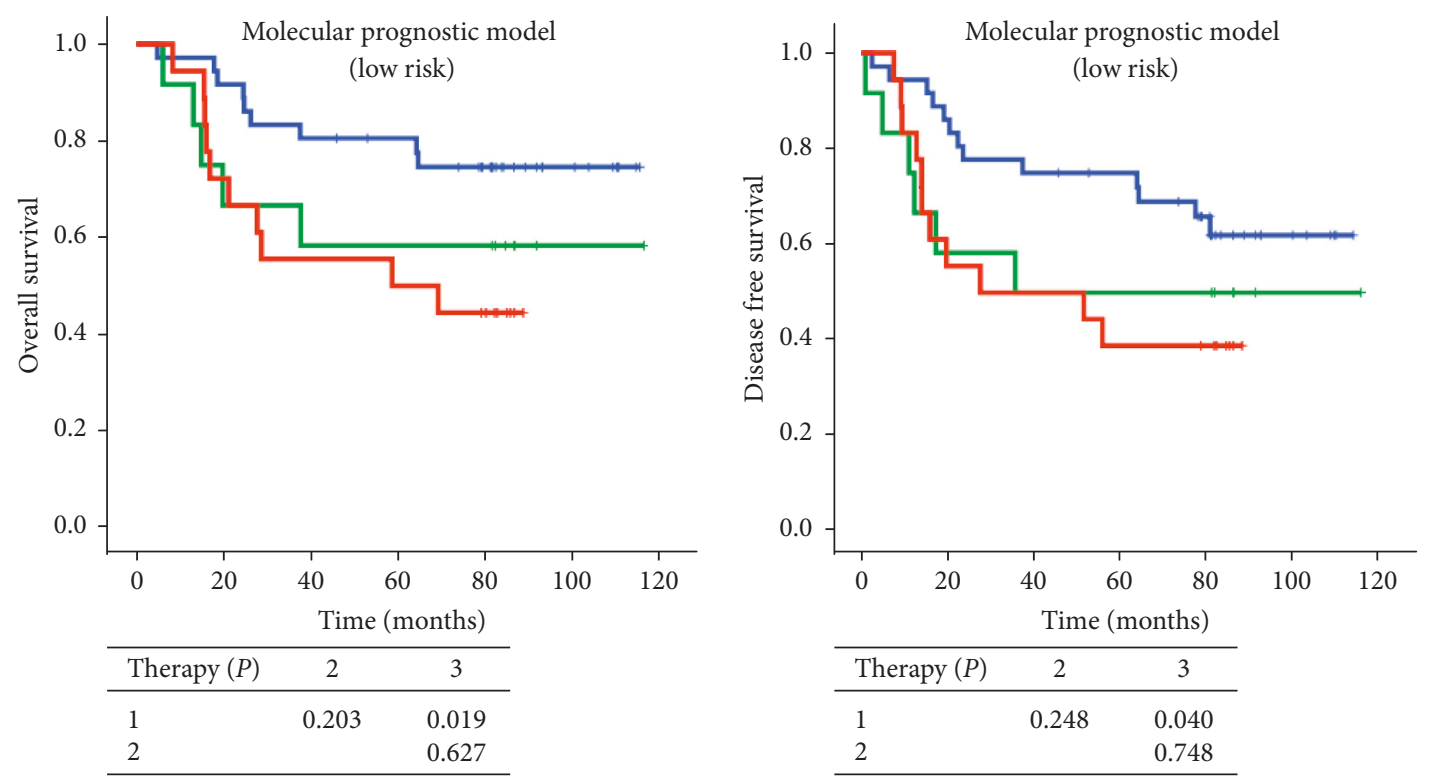

$$
\begin{aligned}
& -1=\text { surgery }(n=36) \\
& -2=\text { surgery }+ \text { radiotherapy }(n=12) \\
& -3=\text { surgery }+ \text { chemotherapy }(n=18)
\end{aligned}
$$

- $1=\operatorname{surgery}(n=36)$

- $2=$ surgery + radiotherapy $(n=12)$

- $3=$ surgery + chemotherapy $(n=18)$

(a)
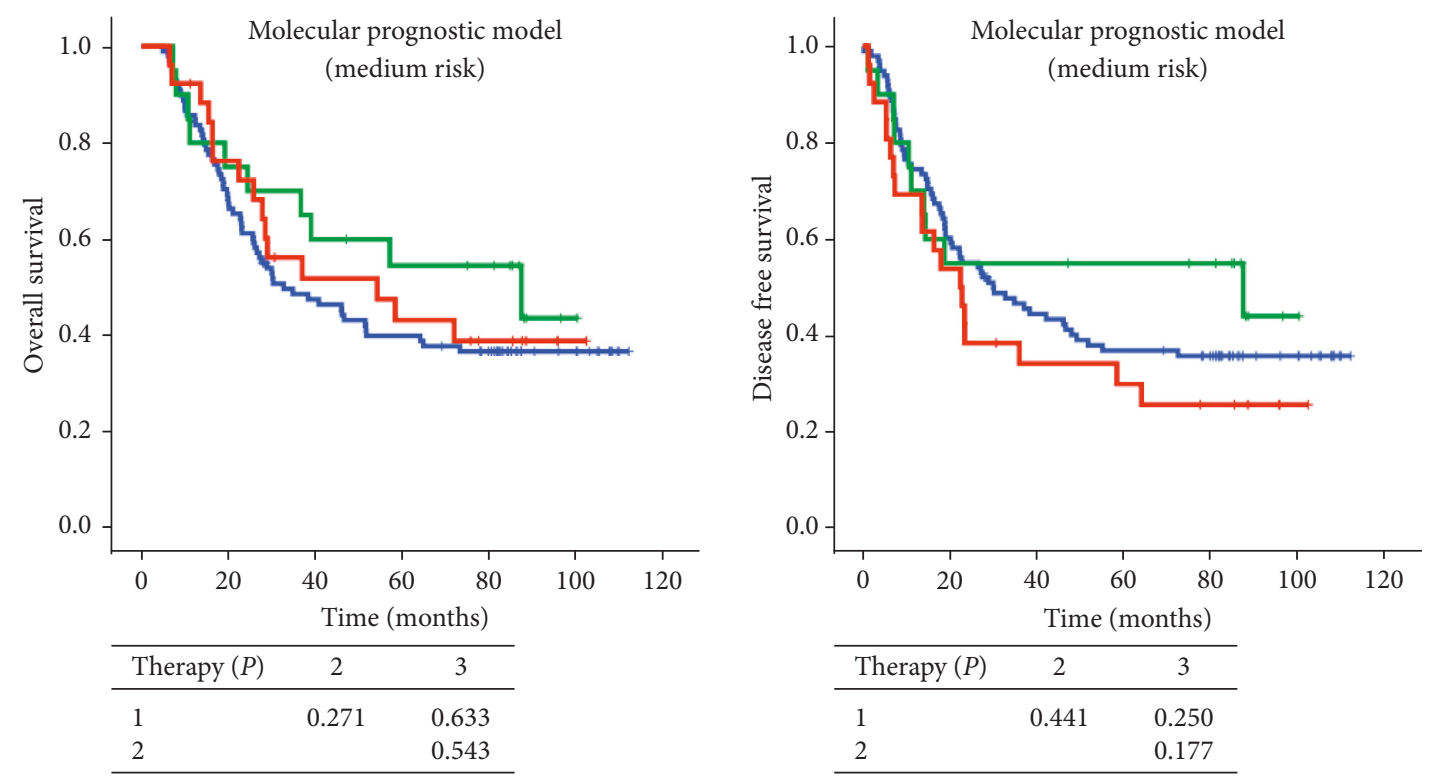

$$
\begin{aligned}
1 & =\operatorname{surgery}(n=98) \\
-2 & =\text { surgery }+ \text { radiotherapy }(n=20) \\
-3 & =\text { surgery }+ \text { chemotherapy }(n=26)
\end{aligned}
$$

$$
\begin{aligned}
1 & =\text { surgery }(n=98) \\
-2 & =\text { surgery }+ \text { radiotherapy }(n=20) \\
-3 & =\text { surgery }+ \text { chemotherapy }(n=26)
\end{aligned}
$$

(b)

Figure 4: Continued. 

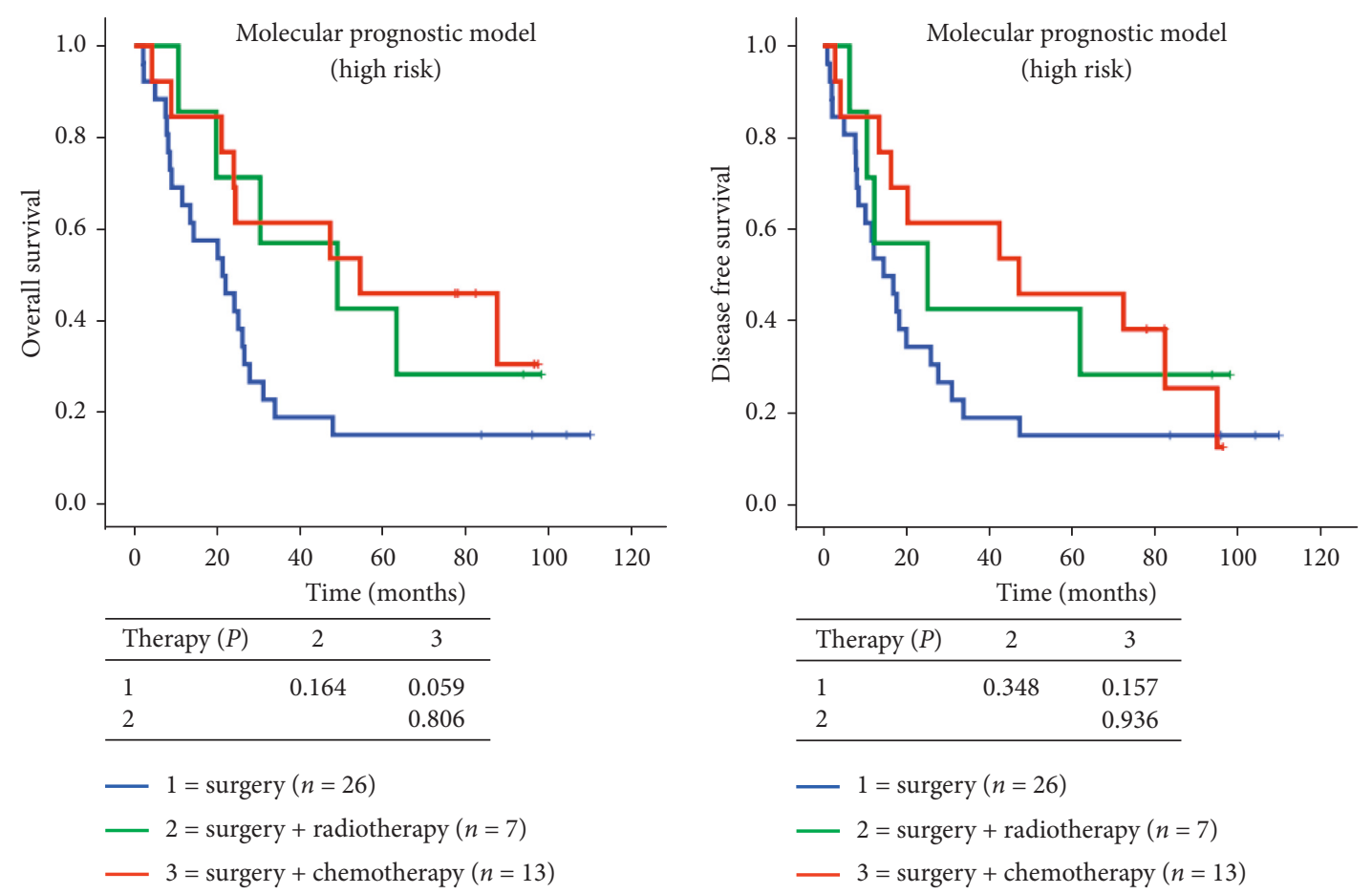

(c)

FIgURE 4: K-M survival curves indicate that radiotherapy and chemotherapy prolonged patients' OS and DFS in high-risk group but shortened patients' survival in low-risk group.

line with the protumorigenic role of ITGA5B1, we are the first to uncover the high expression of this protein in more advanced and metastatic ESCC tumors with unfavorable prognosis. Further studies are needed to delineate the mechanisms behind the deregulation of ITGA5B1 and its biological function in ESCC. PDIA3 has been shown to confer chemo/radioresistance to various types of tumor cells such as ovarian carcinoma $[47,48]$. PDIA3 expression level is correlated with the clinical outcome of patients with ovarian carcinoma who receive chemoradiotherapy, and the sensitivity to paclitaxel can be enhanced by PDIA3 silencing $[47,48]$. In ESCC, we found that PDIA3 decreased gradually with the progress of stage and related to favorable prognosis, which was in accord with the findings in gastric cancer [49], but contrary to those in hepatocellular carcinoma [50]. The favorable prognostic value of PDIA3 in ESCC implies that ESCC patients with high expression of PDIA3 may be more sensitive to chemotherapy such as paclitaxel, but further studies are warranted. These contrasting observations can be attributed to the differences in the carcinogenic machinery between ESCC and other carcinomas.

Taken together, these data suggest that MYC, PDIA3, and ITGA5B1 may serve as potential therapeutic targets for ESCC treatment, and cotargeting of these biomarkers might be more effective than targeting a single biomarker alone. Importantly, this study provides a clinically applicable molecular model that can more precisely predict clinical outcome than pTNM-stage, which may also facilitate the identification of ESCC patients who can benefit from radiotherapy or chemotherapy.

\section{Data Availability}

The clinical data and protein expression used to support the findings of this study are available from the corresponding author upon request.

\section{Conflicts of Interest}

The authors declare no conflicts of interest.

\section{Acknowledgments}

The authors thank all the research staff for their contributions to this project. This work was supported in part by the Natural Science Foundation of China-Guangdong Joint Fund (no. U1601229), the National Science Foundation of China (nos. 81772532 and 81472613), the National Cohort of Esophageal Cancer of China (Grant no. 2016YFC09014000), the Guangdong Esophageal Cancer Institute Science and Technology Program (no. M201714), and the Department of Education, Guangdong Government under the Top-tier University Development Scheme for Research and Control of Infectious Diseases.

\section{Supplementary Materials}

Figure S1: representative images showing the scoring process by the automated quantitative pathology imaging system. Figure S2: predictive value of three genes and the molecular model in validation dataset. Table S1: the clinicopathological 
characteristics of validation dataset of patients with ESCC. (Supplementary Materials)

\section{References}

[1] S. McGuire, "World cancer report 2014. Geneva, Switzerland: World Health Organization, International Agency for Research on Cancer, WHO Press, 2015," Advances in Nutrition, vol. 7, no. 2, pp. 418-419, 2016.

[2] R. L. Siegel, K. D. Miller, and A. Jemal, "Cancer statistics, 2016," CA: A Cancer Journal for Clinicians, vol. 66, no. 1, pp. 7-30, 2016.

[3] F. Kamangar, G. M. Dores, and W. F. Anderson, "Patterns of cancer incidence, mortality, and prevalence across five continents: defining priorities to reduce cancer disparities in different geographic regions of the world," Journal of Clinical Oncology, vol. 24, no. 14, pp. 2137-2150, 2006.

[4] W. Chen, R. Zheng, P. D. Baade et al., "Cancer statistics in China, 2015," CA: A Cancer Journal for Clinicians, vol. 66, no. 2, pp. 115-132, 2016.

[5] P. C. Enzinger and R. J. Mayer, "Esophageal cancer," New England Journal of Medicine, vol. 349, no. 23, pp. 2241-2252, 2003.

[6] M. Tachibana, S. Kinugasa, N. Hirahara, and H. Yoshimura, "Lymph node classification of esophageal squamous cell carcinoma and adenocarcinoma," European Journal of Cardio-Thoracic Surgery, vol. 34, no. 2, pp. 427-431, 2008.

[7] S. Benowitz, "Revised guidelines signal that gene expression profiles are coming of age," JNCI: Journal of the National Cancer Institute, vol. 100, no. 13, pp. 916-917, 2008.

[8] Y. Zhu, M.-X. Zhu, X.-D. Zhang et al., "SMYD3 stimulates EZR and LOXL2 transcription to enhance proliferation, migration, and invasion in esophageal squamous cell carcinoma," Human Pathology, vol. 52, pp. 153-163, 2016.

[9] L.-L. Sun, J.-Y. Wu, Z.-Y. Wu et al., "A three-gene signature and clinical outcome in esophageal squamous cell carcinoma," International Journal of Cancer, vol. 136, no. 6, pp. E569-E577, 2015.

[10] C. He, J. Xu, J. Zhang et al., "High expression of trimethylated histone $\mathrm{H} 3$ lysine 4 is associated with poor prognosis in hepatocellular carcinoma," Human Pathology, vol. 43, no. 9, pp. 1425-1435, 2012.

[11] W. Liu, J.-Z. He, S.-H. Wang et al., "MASAN: a novel staging system for prognosis of patients with oesophageal squamous cell carcinoma," British Journal of Cancer, vol. 118, no. 11, pp. 1476-1484, 2018.

[12] J.-Z. He, Z.-Y. Wu, S.-H. Wang et al., “A decision tree-based combination of ezrin-interacting proteins to estimate the prognostic risk of patients with esophageal squamous cell carcinoma," Human Pathology, vol. 66, pp. 115-125, 2017.

[13] B. Bruce, G. Khanna, L. Ren et al., "Expression of the cytoskeleton linker protein ezrin in human cancers," Clinical \& Experimental Metastasis, vol. 24, no. 2, pp. 69-78, 2007.

[14] M. Curto and A. I. McClatchey, "Ezrin... a metastatic detERMinant?," Cancer Cell, vol. 5, no. 2, pp. 113-114, 2004.

[15] J.-J. Xie, L.-Y. Xu, Y.-M. Xie et al., "Roles of ezrin in the growth and invasiveness of esophageal squamous carcinoma cells," International Journal of Cancer, vol. 124, no. 11, pp. 2549-2558, 2009.

[16] J.-J. Xie, L.-Y. Xu, Z.-Y. Wu et al., "Prognostic implication of ezrin expression in esophageal squamous cell carcinoma," Journal of Surgical Oncology, vol. 104, no. 5, pp. 538-543, 2011.
[17] M. Arpin, D. Chirivino, A. Naba, and I. Zwaenepoel, "Emerging role for ERM proteins in cell adhesion and migration," Cell Adhesion \& Migration, vol. 5, no. 2, pp. 199-206, 2014.

[18] C. V. Dang, "c-MYC target genes involved in cell growth, apoptosis, and metabolism," Molecular and Cellular Biology, vol. 19, no. 1, pp. 1-11, 1999.

[19] X. Wang, Y. Liu, D. Shao et al., "Recurrent amplification of MYC and TNFRSF11B in 8q24 is associated with poor survival in patients with gastric cancer," Gastric Cancer, vol. 19, no. 1, pp. 116-127, 2016.

[20] K. S. Lee, Y. Kwak, K. H. Nam et al., "c-MYC copy-number gain is an independent prognostic factor in patients with colorectal cancer," PLoS One, vol. 10, no. 10, Article ID e0139727, 2015.

[21] H. Sato, S. Minei, T. Hachiya, T. Yoshida, and Y. Takimoto, "Fluorescence in situ hybridization analysis of c-MYC amplification in stage $\mathrm{T}_{3} \mathrm{~N}_{0} \mathrm{M}_{0}$ prostate cancer in Japanese patients," International Journal of Urology, vol. 13, no. 6, pp. 761-766, 2006.

[22] M. Jung, A. J. Russell, B. Liu et al., "A myc activity signature predicts poor clinical outcomes in myc-associated cancers," Cancer Research, vol. 77, no. 4, pp. 971-981, 2017.

[23] Y.-C. Chuan, D. Iglesias-Gato, L. Fernandez-Perez et al., "Ezrin mediates c-MYC actions in prostate cancer cell invasion," Oncogene, vol. 29, no. 10, pp. 1531-1542, 2010.

[24] E. Perri, S. Parakh, and J. Atkin, "Protein disulphide isomerases: emerging roles of PDI and ERp57 in the nervous system and as therapeutic targets for ALS," Expert Opinion on Therapeutic Targets, vol. 21, no. 1, pp. 37-49, 2017.

[25] F. S. Ramos, L. T. R. Serino, C. M. S. Carvalho et al., "PDIA3 and PDIA6 gene expression as an aggressiveness marker in primary ductal breast cancer," Genetics and Molecular Research, vol. 14, no. 2, pp. 6960-6967, 2015.

[26] M. Kullmann, G. V. Kalayda, M. Hellwig et al., "Assessing the contribution of the two protein disulfide isomerases PDIA1 and PDIA3 to cisplatin resistance," Journal of Inorganic Biochemistry, vol. 153, pp. 247-252, 2015.

[27] A. Ménoret, D. A. Drew, S. Miyamoto, M. Nakanishi, A. T. Vella, and D. W. Rosenberg, "Differential proteomics identifies PDIA3 as a novel chemoprevention target in human colon cancer cells," Molecular Carcinogenesis, vol. 53, no. S1, pp. E11-E22, 2014.

[28] K. R. Legate and R. Fassler, "Mechanisms that regulate adaptor binding to beta-integrin cytoplasmic tails," Journal of Cell Science, vol. 122, no. 2, pp. 187-198, 2009.

[29] R. Zaidel-Bar, S. Itzkovitz, A. Ma'ayan, R. Iyengar, and B. Geiger, "Functional atlas of the integrin adhesome," Nature Cell Biology, vol. 9, no. 8, pp. 858-867, 2007.

[30] J.-C. Guo, Y.-M. Xie, L.-Q. Ran et al., "L1CAM drives oncogenicity in esophageal squamous cell carcinoma by stimulation of ezrin transcription," Journal of Molecular Medicine, vol. 95, no. 12, pp. 1355-1368, 2017.

[31] R. L. Camp, M. Dolled-Filhart, and D. L. Rimm, "X-tile: a new bio-informatics tool for biomarker assessment and outcomebased cut-point optimization," Clinical Cancer Research, vol. 10, no. 21, pp. 7252-7259, 2004.

[32] C. M. Fife, J. A. McCarroll, and M. Kavallaris, "Movers and shakers: cell cytoskeleton in cancer metastasis," British Journal of Pharmacology, vol. 171, no. 24, pp. 5507-5523, 2014.

[33] Y. Wang, Z. Lin, L. Sun et al., “Akt/ezrin Tyr353/NF- $\kappa$ B pathway regulates EGF-induced EMT and metastasis in tongue squamous cell carcinoma," British Journal of Cancer, vol. 110, no. 3, pp. 695-705, 2014. 
[34] H. Zeng, L. Xu, D. Xiao et al., "Altered expression of ezrin in esophageal squamous cell carcinoma," Journal of Histochemistry \& Cytochemistry, vol. 54, no. 8, pp. 889-896, 2006.

[35] D. Kienle, T. Katzenberger, G. Ott et al., "Quantitative gene expression deregulation in mantle-cell lymphoma: correlation with clinical and biologic factors," Journal of Clinical Oncology, vol. 25, no. 19, pp. 2770-2777, 2007.

[36] W. Zheng, C. Jiang, and R. Li, "Integrin and gene network analysis reveals that ITGA5 and ITGB1 are prognostic in nonsmall-cell lung cancer," OncoTargets and Therapy, vol. 9, pp. 2317-2327, 2016.

[37] A. M. Staiger, M. Ziepert, H. Horn et al., "Clinical impact of the cell-of-origin classification and the MYC/BCL2 dual expresser status in diffuse large B-cell lymphoma treated within prospective clinical trials of the German high-grade nonHodgkin's lymphoma study group," Journal of Clinical Oncology, vol. 35, no. 22, pp. 2515-2526, 2017.

[38] N. Gassler, I. Herr, M. Keith et al., "Wnt-signaling and apoptosis after neoadjuvant short-term radiotherapy for rectal cancer," International Journal of Oncology, vol. 25, no. 6, pp. 1543-1549, 2004.

[39] Y. Kinoshita and E. M. Johnson, "Site-specific loading of an MCM protein complex in a DNA replication initiation zone upstream of the c-MYC gene in the HeLa cell cycle," Journal of Biological Chemistry, vol. 279, no. 34, pp. 35879-35889, 2004.

[40] C. E. Nesbit, L. E. Grove, X. Yin, and E. V. Prochownik, "Differential apoptotic behaviors of c-myc, N-myc, and L-myc oncoproteins," Cell Growth \& Differentiation, vol. 9, no. 9, pp. 731-741, 1998.

[41] E. V. Prochownik, "c-MYC as a therapeutic target in cancer," Expert Review of Anticancer Therapy, vol. 4, no. 2, pp. 289302, 2004.

[42] E. Morelli, L. Biamonte, C. Federico et al., "Therapeutic vulnerability of multiple myeloma to MIR17PTi, a first-inclass inhibitor of pri-miR-17-92," Blood, vol. 132, no. 10, pp. 1050-1063, 2018.

[43] Y. Zhang, J. Ding, C. Xu et al., "rBMSCs/ITGA5B1 promotes human vascular smooth muscle cell differentiation via enhancing nitric oxide production," International Journal of Stem Cells, vol. 11, no. 2, pp. 168-176, 2018.

[44] H.-Y. Chen, L. Pan, H.-L. Yang et al., "Integrin alpha5beta1 suppresses rBMSCs anoikis and promotes nitric oxide production," Biomedicine \& Pharmacotherapy, vol. 99, pp. 1-8, 2018.

[45] S. M. Hrycaj, L. Marty-Santos, C. Cebrian et al., "Hox5genes direct elastin network formation during alveologenesis by regulating myofibroblast adhesion," Proceedings of the $\mathrm{Na}$ tional Academy of Sciences, vol. 115, no. 45, pp. E10605E10614, 2018.

[46] Q. Gao, Z. Yang, S. Xu et al., "Heterotypic CAF-tumor spheroids promote early peritoneal metastatis of ovarian cancer," The Journal of Experimental Medicine, vol. 216, no. 3, pp. 688-703, 2019.

[47] S. Li, X. Zhao, S. Chang, Y. Li, M. Guo, and Y. Guan, "ERp57small interfering RNA silencing can enhance the sensitivity of drug resistant human ovarian cancer cells to paclitaxel," International Journal of Oncology, vol. 54, no. 1, pp. 249-260, 2019.

[48] H. Zou, C. Wen, Z. Peng et al., "P4HB and PDIA3 are associated with tumor progression and therapeutic outcome of diffuse gliomas," Oncology Reports, vol. 39, no. 2, pp. 501-510, 2018.

[49] T. Shimoda, R. Wada, S. Kure et al., "Expression of protein disulfide isomerase A3 and its clinicopathological association in gastric cancer," Oncology Reports, vol. 41, no. 4, pp. 2265-2272, 2019.

[50] R. Kondo, K. Ishino, R. Wada et al., "Downregulation of protein disulfide-isomerase A3 expression inhibits cell proliferation and induces apoptosis through STAT3 signaling in hepatocellular carcinoma," International Journal of Oncology, vol. 54, no. 4, pp. 1409-1421, 2019. 


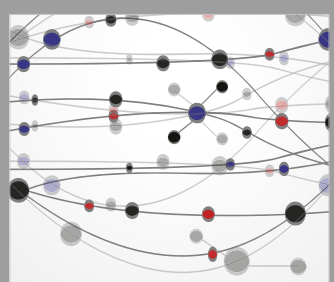

The Scientific World Journal
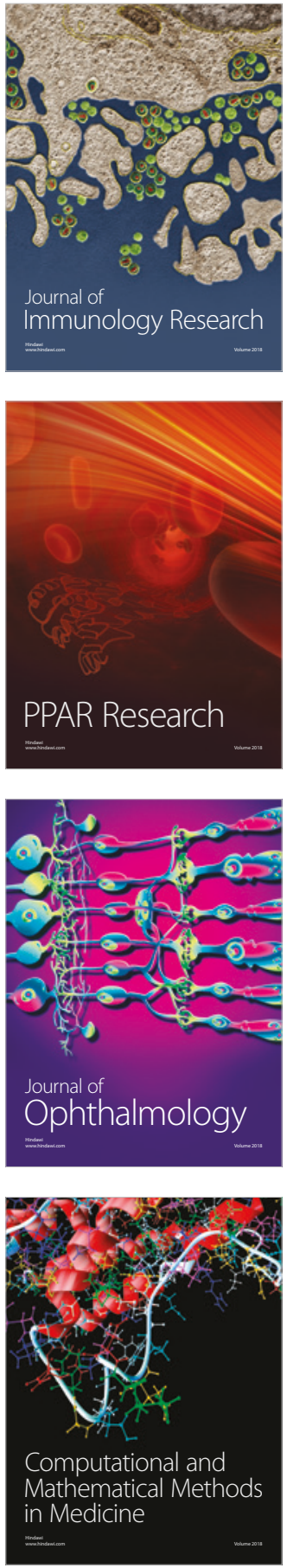

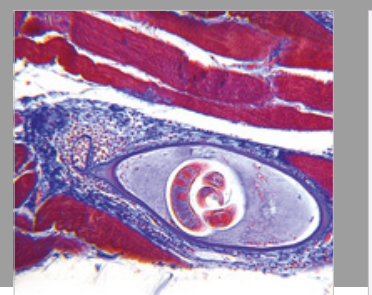

Gastroenterology Research and Practice

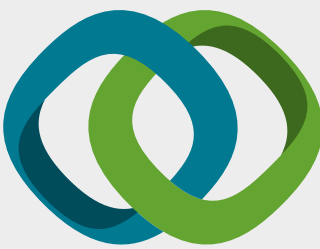

\section{Hindawi}

Submit your manuscripts at

www.hindawi.com
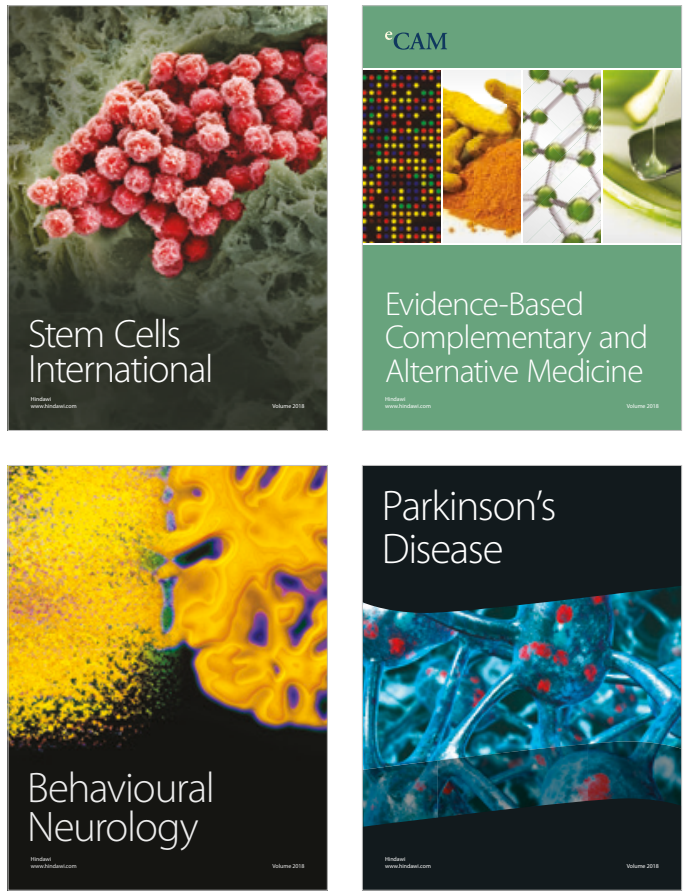

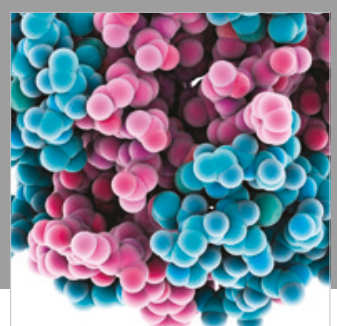

ournal of

Diabetes Research

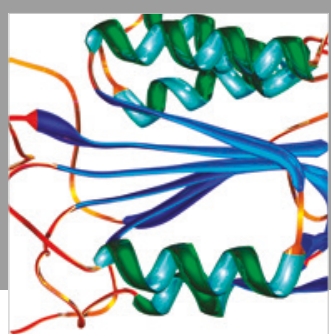

Disease Markers
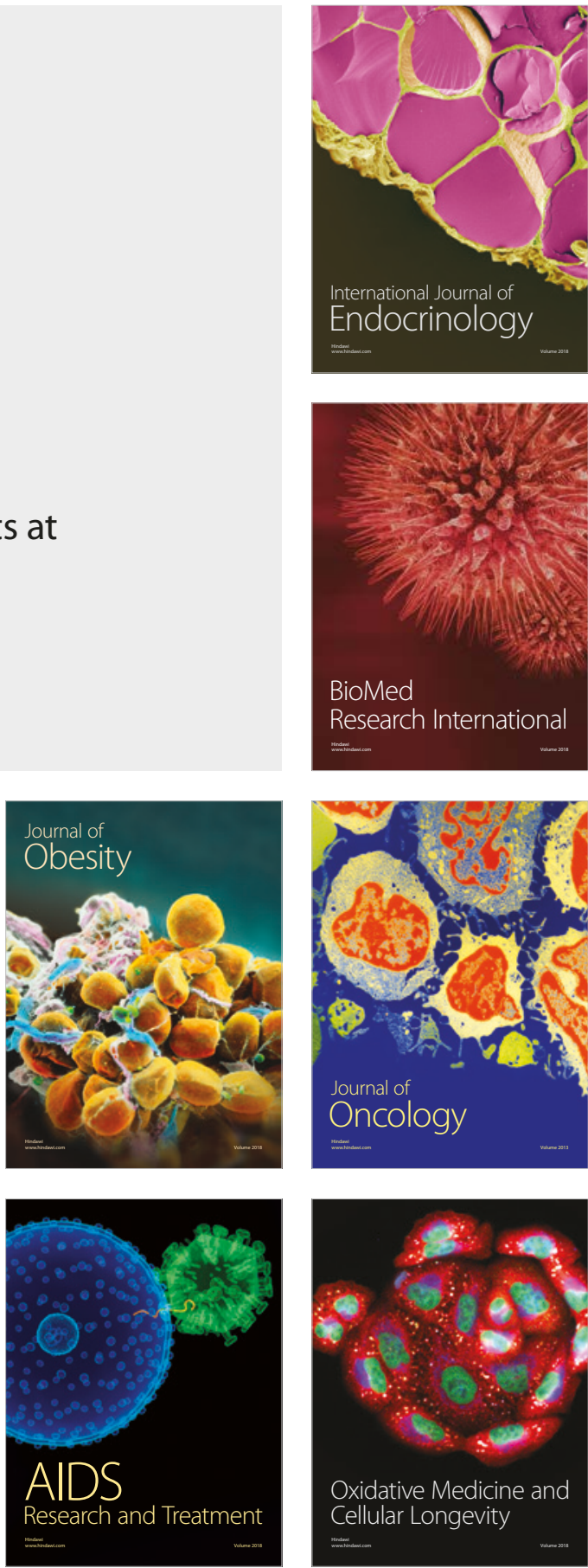